\title{
INFLUENCE OF ATOMIC AND MOLECULAR HYDROGEN IN SILUMINS MELTS ON THEIR MECHANICAL PROPERTIES
}

\author{
V. N. Baranov,,$^{1,2}$ V. B. Deev, ${ }^{3}$ E. G. Partyko, ${ }^{1,4}$ S. V. Belyaev, ${ }^{1,5}$ \\ P. O. Yur'ev, ${ }^{1,6}$ and E.S. Prusov ${ }^{7}$
}

UDC 621.74

\begin{abstract}
We study the influence of gas porosity caused by the presence of dissolved hydrogen on the mechanical properties of Al-Si alloys. The results are obtained by testing cast samples with identical contents of hydrogen and a given (atomic or molecular) form of hydrogen inclusions. The dependence of the mechanical properties of alloys on the density index is statistically established. It is shown that if the density index increases and hydrogen is released in the atomic form, the mechanical properties remain practically unchanged, whereas the presence of hydrogen in the molecular form in silumin deteriorates the mechanical properties of the metal.
\end{abstract}

Keywords: hydrogen; atomic and molecular state; silumins; density index; mechanical properties.

Gaseous impurities (hydrogen, oxygen, and nitrogen) in alloys in the solid and liquid states are present in the form of inclusions of excess phases. Hydrogen, nitrogen, and oxygen compounds may form gas inclusions (bubbles) in solid alloys. As a characteristic feature of the analyzed elements, we can mention the fact that, under certain conditions, they can form interstitial solid solutions in the lattice of the alloy. Gaseous hydrogen, oxygen, and nitrogen compounds are sorbed on the metal surface as a result of the processes of physical absorption, dissociate into atoms, and are accumulated on structural defects [1-3]. If the concentration of an impurity exceeds its solubility at a given temperature, then we observe the formation of a secondary solid solution, i.e., of a hydride, oxide, or nitride phase $[4,5]$.

Hydrogen is one of the most significant gaseous impurities, which negatively affect the mechanical and technological properties of the products made of aluminum alloys and composites based on these alloys [6-12]. As compared with the other gases present in aluminum alloys, hydrogen has the highest solubility in liquid aluminum [13]. Under certain conditions, hydrogen dissolved in the alloy promotes the formation of gas and gasshrinkage porosity that becomes more intense as the hydrogen content increases [14]. In particular, this kind of porosity is formed in the course of crystallization of an aluminum alloy containing dissolved hydrogen due to the difference between the solubilities of hydrogen in solid and liquid phases. Hydrogen porosity negatively affects the mechanical properties of castings and ingots because internal micropores play the role of local stress concentrators promoting the processes of crack initiation and propagation under loading [15].

\footnotetext{
${ }^{1}$ Siberian Federal University, Krasnoyarsk, Russia.

2 E-mail: vnbar79@mail.ru.

${ }^{3}$ Wuhan Textile University, Wuhan, China, and "MISiS" National Research Technological University, Moscow, Russia; e-mail: deev.vb@mail.ru.

${ }^{4}$ E-mail: Elforion@mail.ru.

5-mail: 244812@mail.ru.

6-mail: 771466@mail.ru.

${ }^{7}$ A. Stoletov and N. Stoletov Vladimir State University, Vladimir, Russia; e-mail: eprusov@mail.ru.
}

Translated from Metallurg, Vol. 63, No. 5, pp. 81-86, May, 2019. Original article submitted January, 16, 2019. 


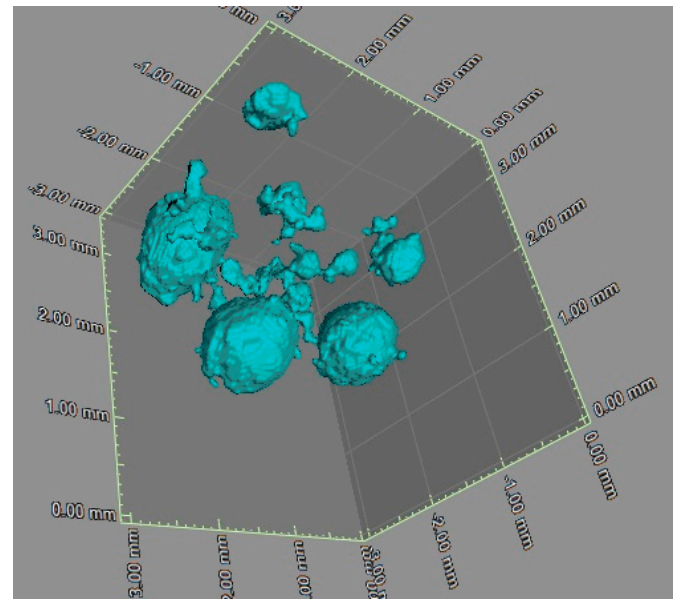

(a)

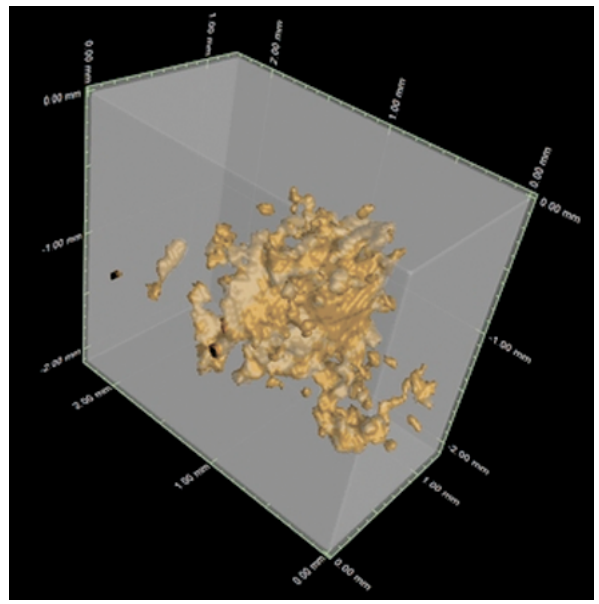

(b)

Fig. 1. Three-dimensional tomographic images of gas (a) and shrinkage (b) pores in a silumin casting.

It is known that the morphology of pores in an alloy directly depends on the process of their formation: gas pores, as a rule, have spherical shapes, while the shrinkage pores are, in fact, interdendrite cavities and have irregular geometry [16]. This can be illustrated by the presented tomographic images obtained in [17] with the help of a Nanomex installation equipped with the function of tomography (GE Measurement \& Control, GmbH, Germany) (Fig. 1). It is assumed that gas pores are initiated in the interdendrite spaces when the limit of solubility of hydrogen in the early stages of crystallization of the aluminum alloy in the quasiequilibrium two-phase zone is exceeded, whereas the shrinkage cavities are formed closer to the end of the process of solidification. This explains the morphological features of various types of porosity in cast products and ingots and, in particular, the spherical shape of hydrogen pores can be caused by their formation and growth in the open dendrite skeleton [18-21].

Depending on the form in which hydrogen is present in the melt, it exerts different influence on the properties of alloys and the products made of these alloys. In the products, it is important to know the distribution of gas impurities over the micro- and macrostructure and their redistribution in the course of operation conditions under the influence of the ambient temperature and mechanical loads [22, 23].

The aim of the present work is to study the influence of the atomic and molecular forms of hydrogen in silumins on the mechanical properties of cast silumin products.

The specimens were produced by the method of low-pressure casting in a GIMA Amatic-800 (Germany) casting machine from A413.1 alloy (ASTM) under the conditions of the "KiK" Plant of Wheel Disks. The chemical composition of A413.1 alloy is as follows, wt.\%: $0.3 \mathrm{Fe}, 12 \mathrm{Si}, 0.3 \mathrm{Mn}, 0.05 \mathrm{Ti}, 0.3 \mathrm{Cu}, 0.05 \mathrm{Zr}$, $0.05 \mathrm{Mg}, 0.2 \mathrm{Zn}, 2.7$ impurities, and balance Al.

This method of casting was chosen with an aim to form zones with hydrogen pores of different shapes in the cast products. The formation of structures in different zones of the casting occurred under the conditions of controlled forced air cooling. The process of hydrogen release in different forms (atomic and molecular) was realized by varying the cooling rates and the shape of hydrogen pores was recorded in a Zeiss EVO-50 scanning electron microscope.

At present, in Russia, the hydrogen content of aluminum alloys is often determined by the method of vacuum heating in an AV-1 device. The main disadvantage of this procedure is the duration of analysis. This is why it cannot be used under the commercial conditions of production of alloys and casting of products as a rapid test method. 


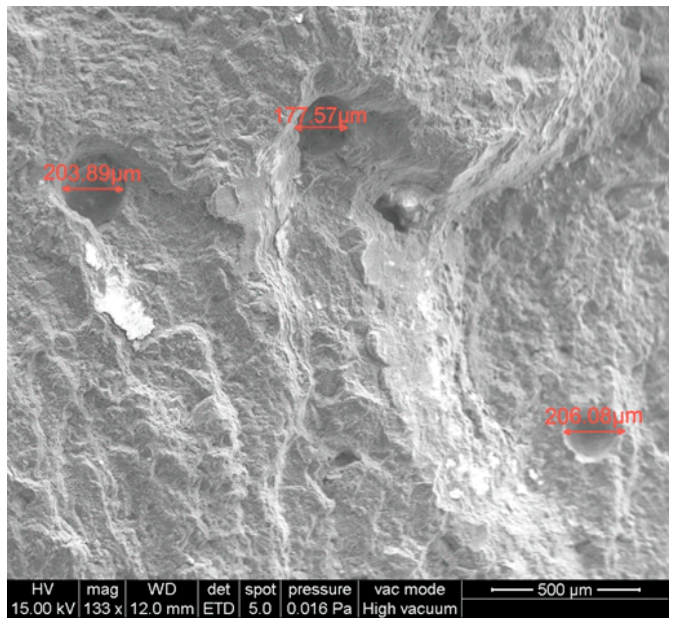

(a)

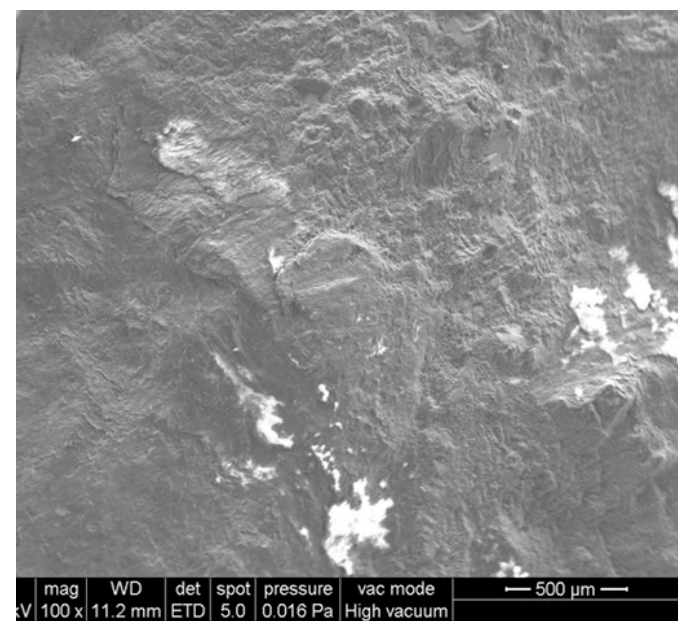

(b)

Fig. 2. Specimens with molecular (a) and atomic (b) forms of hydrogen inclusions.

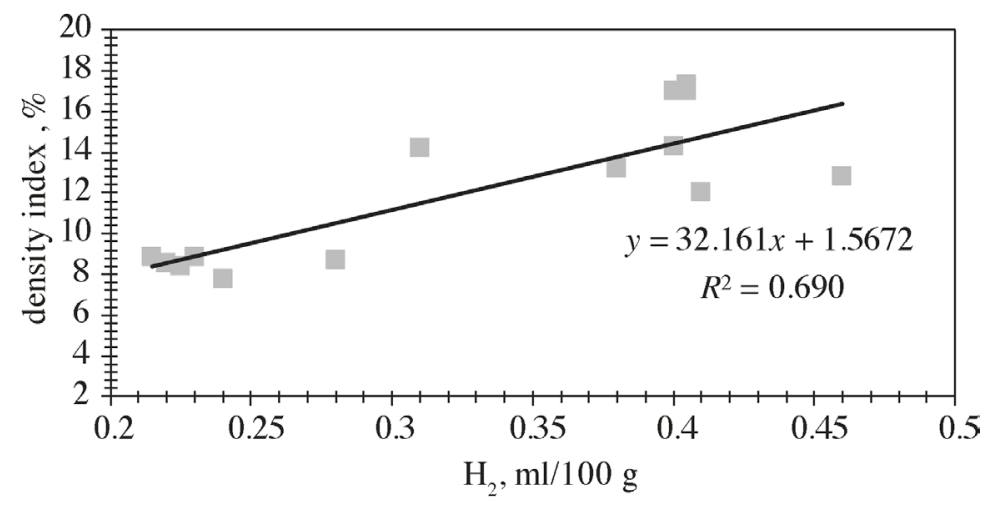

Fig. 3. Dependence of the density index on the hydrogen content.

In this connection, we propose to use a rapid testing method of density index (realized on a $3 \mathrm{vt}$ device) as an indirect method for the evaluation of the hydrogen content. The essence of the method of density index can be described as follows: The reference samples of the alloy are taken and crystallized under different conditions: a part of samples is crystallized under atmospheric pressure, whereas the other part is crystallized under the conditions of rarefaction. The difference between the values of density for the samples crystallized in air and under a pressure of 80 mbar is an index that approximately reflects the hydrogen content of the alloy [24].

The standard samples were prepared for the investigation of their mechanical properties in a WABECO P6000 machine. The base length of the specimens was equal to $60 \mathrm{~mm}$ and the diameter of their working part to $12 \mathrm{~mm}$.

The mechanical properties of the specimens were determined in a WDW-10 universal testing machine. The values of the mechanical characteristics of the samples with molecular and atomic forms of hydrogen were determined according to ISO 6892 and the number of samples was equal to 350. The statistical analysis was carried out by using the STATISTICA software.

The presence of hydrogen inclusions of certain shapes in the obtained samples was confirmed with the help of scanning electron microscopy (Fig. 2). According to the results of measurements of the density index and the hydrogen content of the alloy, we plotted a the curve depicted in Fig. 3. 
From the theoretical point of view, the correlation dependence of the density index on the hydrogen content must approach 1 if these parameters are proportional to each other. The experimental results demonstrate that the determination factor $R^{2}$ specifies the mean relationship between the values of density index and hydrogen content. It is assumed that the density index characterizes not only the variations of the hydrogen content but also the degree of pollution of the melt by nonmetallic inclusions (NI).

In the course of preparation of melt, we observe its intense saturation with hydrogen, nitrogen, and oxygen. The aluminum melt interacts with oxygen to form $\mathrm{Al}_{2} \mathrm{O}_{3}$ in the form of oxide spots and suspensions, which play the role of strong hydrogen adsorbers [25-27]. Since the surface of oxide spots is loose, it adsorbs significant amounts of hydrogen and creates conditions for the formation of pores in the course of solidification of the specimen under low pressure. Due to the partial presence of hydrogen in oxide spots in the process of evaluation of the density index under the conditions of rarefaction, an additional hydrogen release from the oxide spots may also occur simultaneously with the floating of pores on the surfaces of the samples. This is why the density index of the samples depends on the amount of absorbed hydrogen and the amount of suspensions of oxide spots penetrating into the melt in the course of its preparation. Thus, the density index can be regarded as a qualitative method for the evaluation of the degree of pollution with NI and hydrogen.

The results of statistical evaluation of the data of measurements of the mechanical properties of specimens of silumins for different states of hydrogen present in melt are shown in Fig. 4.

The formation of hydrogen-induced porosity in aluminum strongly depends not only on the rates of cooling and solidification but also on the presence of nucleation centers of hydrogen release, such as oxides entrapped in the melt. This is why, for the formation of porosity, the content of dissolved hydrogen must significantly exceed the solubility of hydrogen in solid aluminum.

It should be emphasized that, in the experiments aimed at the evaluation of the influence of hydrogen on the mechanical properties of aluminum and its alloys, it is difficult to isolate the influence of hydrogen in the pure form because porosity can be also caused by the shrinkage phenomena.

The obtained results demonstrate that the molecular form of hydrogen inclusions sharply decreases the fracture resistance and does not exert any noticeable influence on plasticity. Thus, it can be assumed that a significant influence on the level of mechanical properties of castings is exerted solely by relatively large gas and gasshrinkage pores. The ambiguous character of the dependence of relative elongation on porosity is caused by the influence of the following factors on the level of porosity:

- porosity that decreases the cross section of the specimen;

- pressure of molecular hydrogen in the pores, which facilitates the fracture mechanism;

- decomposition of a solid solution oversaturated with atomic hydrogen.

We now consider the structure of fracture surfaces obtained as a result of static loading of cylindrical specimens. The fractures of specimens with molecular form of hydrogen are perpendicular to the axis of tension (Figs. 5a, c). The analysis of the fractographic features of the fractures of specimens demonstrates that the specimens fail by the mechanism of intercrystalline fracture and, to a larger extent, in a ductile way. At large magnifications, we observe flat crests, which form local shrinkage cavities directed along the macrograins, and detect pores of released hydrogen. In the fracture surfaces of specimens with atomic form of hydrogen, the microscopic surface topography is characterized by a lineage pit structure (Figs. 5b, d).

Thus, comparing the results of investigation of cracks in the obtained specimens with different forms of hydrogen inclusions, we detect noticeable differences not only in the characteristics of strength but also in the macrostructure. The fracture of specimens with molecular form of hydrogen occurs with the formation of crests 
(1)

(a)

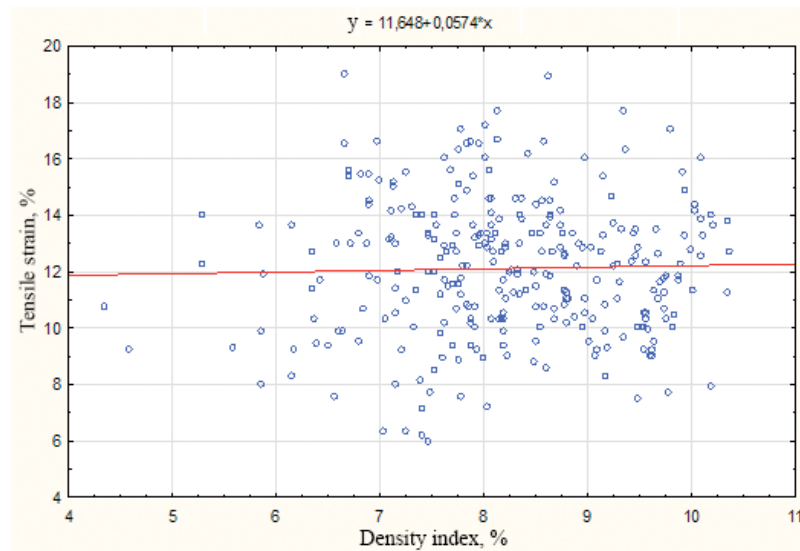

(b)

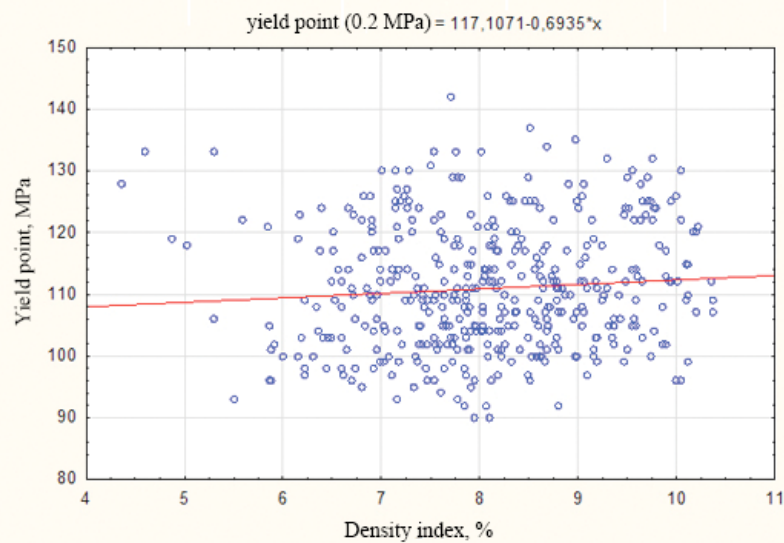

(c)

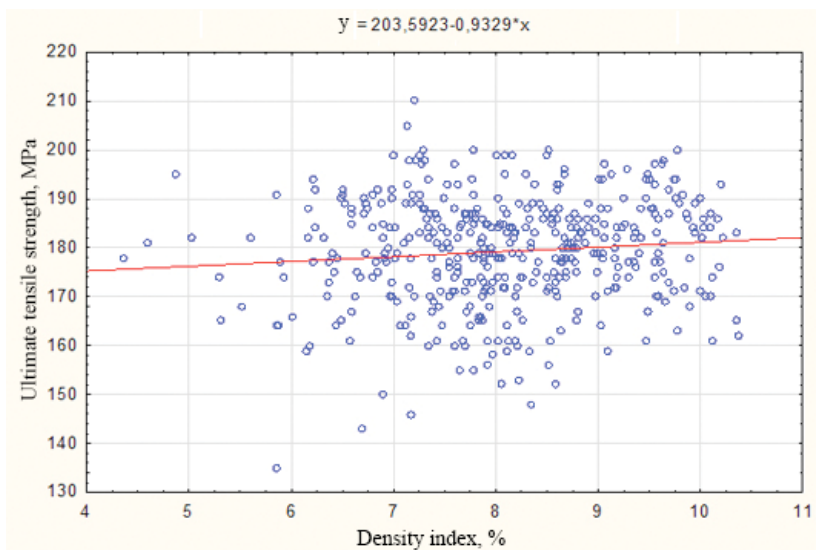

(2)
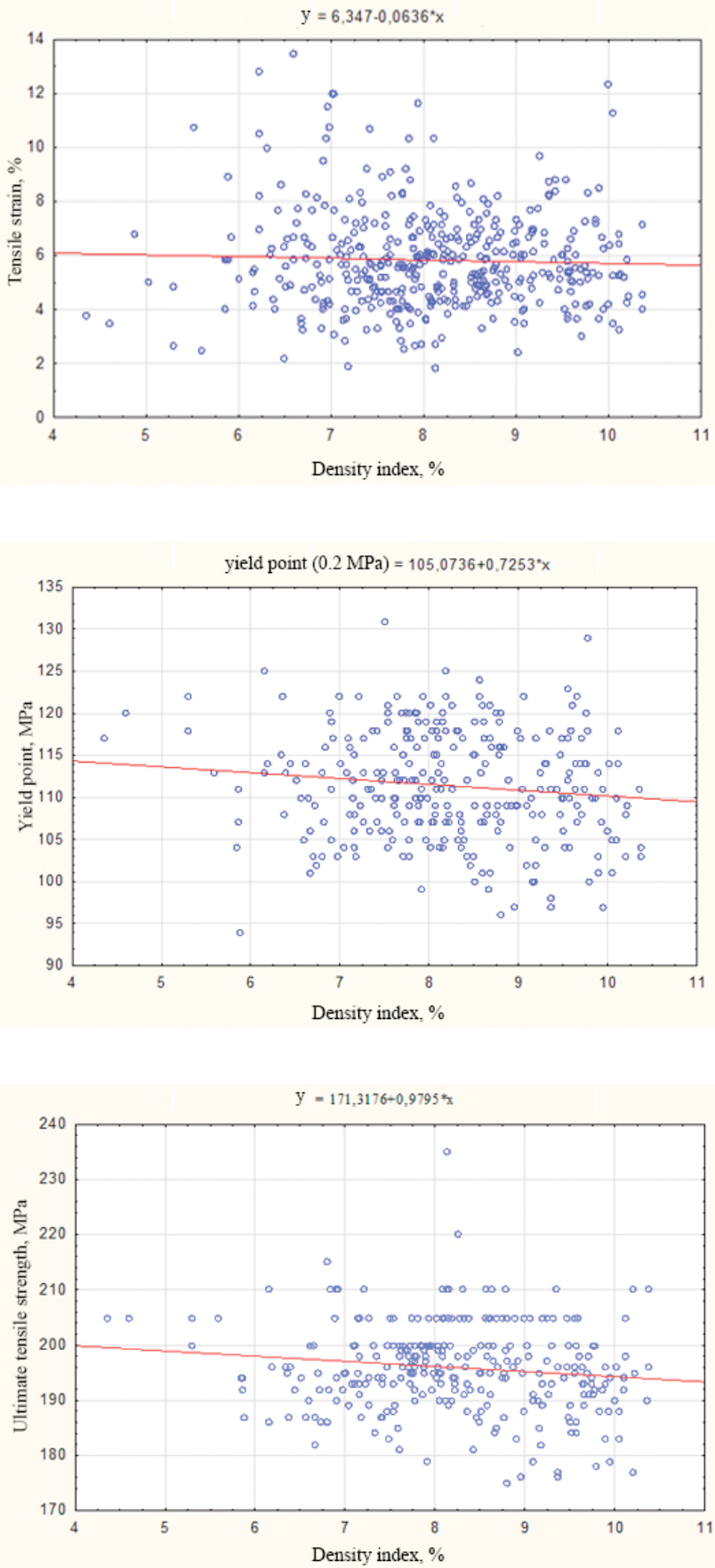

Fig. 4. Statistical analyses of the mechanical properties of samples with atomic (1) and molecular (2) forms of hydrogen inclusions: (a) relative elongation; (b) yield strength; (c) ultimate tensile strength.

and porosity with sizes of about $200 \mu \mathrm{m}$. The fracture of specimens with atomic form of hydrogen is accompanied by the formation of a pit microscopic surface topography, which reveals the ductile character of the fracture processes. 


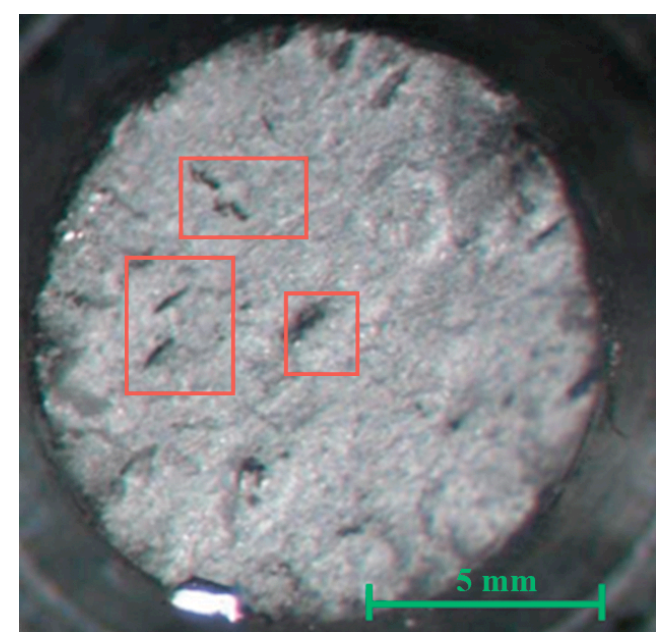

(a)

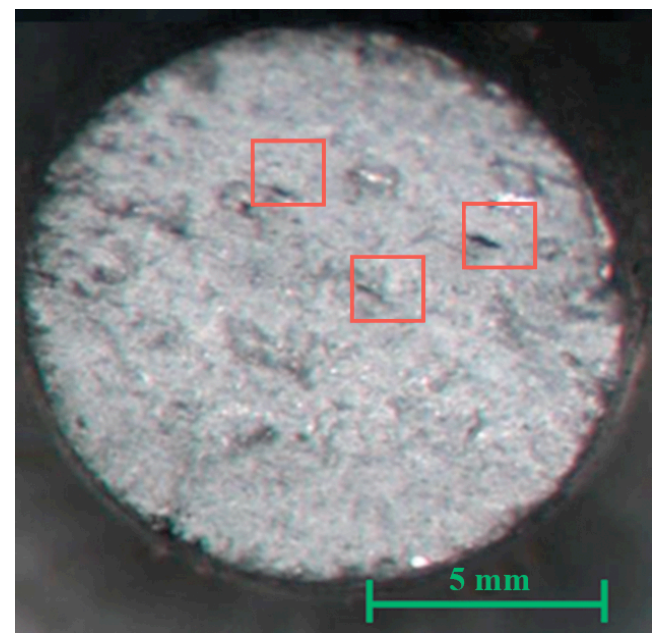

(c)

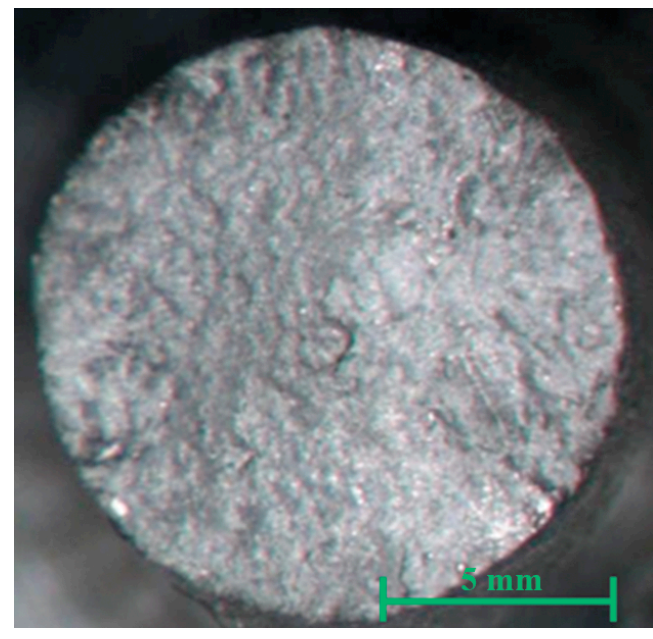

(b)

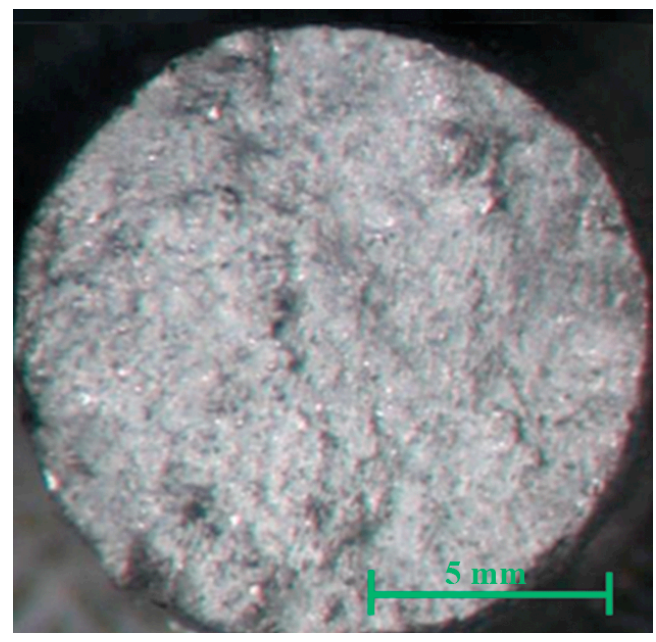

(d)

Fig. 5. Macrostructures of the specimens with molecular (a), (c) and atomic (b), (d) forms of hydrogen inclusions.

The macrostructures of specimens after tensile tests obtained in the longitudinal direction are characterized by the presence of a significant difference between the numbers and sizes of pores. Thus, in specimens with atomic form of hydrogen, the pore sizes do not exceed $650 \mu \mathrm{m}$, whereas in specimens with molecular form of hydrogen, the mean size of pores is $2 \mathrm{~mm}$.

\section{CONCLUSIONS}

The accumulated results demonstrate that the porosity caused by the presence of hydrogen in the molecular form sharply decreases the plasticity and ultimate tensile strength of the material. The character of porosity also exerts a significant influence, namely, large spherical pores substantially deteriorate the mechanical properties. The results of evaluation of the mechanical properties are in good agreement with the data of metallographic investigations of the fracture surfaces of specimens after tensile tests and the values of the coefficient of pollution. 
Since the method of density index is used for the qualitative evaluation of the degree of pollution of the alloy with hydrogen, it is possible to conclude that the mechanical properties remain almost unaffected as the density index increases and hydrogen is released in the atomic form. At the same, the presence of hydrogen in the molecular form deteriorates the mechanical properties of the specimens.

The present work was performed within the framework of the Project 14.578.21.0193 "Development of the Theoretical and Technological Solutions for Lowering the Amount of Hydrogen in the Compositions of Aluminum and Low Aluminum Alloys" of the Federal Purpose-Oriented Program "Investigations and Developments in the Priority Directions of the Scientific and Technological Complex of Russia for 2014-2020" under the Financial Support of the Russian Ministry of Education and Science. The unique identifier of the agreement is RFMEFI57816X0193.

\section{REFERENCES}

1. Y. Liu, Y. Dai, J. Wang, et al., "Structure of liquid aluminum and hydrogen absorption,” J. Wuhan Univ. Technol., 26, No. 1, 93-97 (2011).

2. Y. Liu, B. Sun, Y. Dai, and J. Wang, "First principle study on hydrogen diffusion in degassing," Key Eng. Mater., 474, 1384-1387 (2011).

3. Y. Liu, Y. Dai, J. Wang, et al., "Hydrogen diffusion in aluminum melts: An ab initio molecular dynamics study," J. Wuhan Univ. Technol., 27, No. 3, 560-567 (2012).

4. J. Roučka and J. Hotař, "Controlled precipitation gaseous cavities in aluminum castings,” Arch. Foundry Eng., 15, No. 4, 124-128 (2015).

5. M. Brůna, A. Sládek, and L. Kucharčík, "Formation of porosity in Al-Si Alloys," Arch. Foundry Eng., 12, No. 1, 5-8 (2012).

6. M. Brůna and A. Sládek, "Hydrogen analysis and effect of filtration on final quality of castings from aluminum alloy AlSi7 Mg0,3," Arch. Foundry Eng., 11, No. 1, 5-10 (2011).

7. Y. Li, Z. B. Xu, and J. M. Zeng, "Effect of hydrogen content on impact property of A357 Alloy," Mater. Sci. Forum, 704-705, 1201-1204 (2011).

8. J. M. Zeng, D. Z. Li, Z. B. Xu, and Y. B. Wang, "Hydrogen diffusion in molten aluminum A206 casting alloy," Adv. Sci. Lett., 4, 1740-1745 (2011).

9. V. B. Deev, K. V. Ponomareva, and A. S. Yudin, "Investigation into the density of polystyrene foam models when implementing the resource-saving fabrication technology of thin-wall aluminum sheet," Russ. J. Non-Ferr. Met., 56, No. 3, 283-286 (2015).

10. V. B. Deev, V. A. Degtyar, A. I. Kutsenko, et al., "Resource-saving technology for the production of cast aluminum alloys," Steel Translat., 37, No. 12, 991-994 (2007).

11. A. A. Kolonakov, A. V. Kukharenko, V. B. Deev, and A. A. Abaturova, "Structure and chemical composition of the AK12MMgN piston alloy fabricated based on various charges," Russ. J. Non-Ferr. Met., 56, No. 4, 428-433 (2015).

12. E. Mosisa, V. Yu. Bazhin, and S. A. Savchenkov, "Review on nanoparticle reinforced aluminum metal matrix composites," Res. J. Appl. Sci., 11, No. 5, 188-196 (2016).

13. M. Felberbaum, E. Landry-Désy, L. Weber, and M. Rappaz, "Effective hydrogen diffusion coefficient for solidifying aluminum alloys," Acta Mater., 59, No. 6, 2302-2308 (2011).

14. L. Yao, S. Cockcroft, J. Zhu, and C. Reilly, "Modeling of microporosity size distribution in aluminum alloy A356," Met. Mater. Trans. A, 42, No. 13, 4137-4148 (2011).

15. J. A. Dantzig and M. Rappaz, Solidification, EPFL Press (2017).

16. G. Nicoletto, G. Anzelottia, and R. Konečná, "X-ray computed tomography vs. metallography for pore sizing and fatigue of cast Alalloys," Proced. Eng., 2, No. 1, 547-554 (2010).

17. E. S. Prusov and V. A. Kopytov, "Experience of application of the computer tomography to the quality control of castings and semifinished items," in: Abstr. of the 3rd Internat. Conf. on Tomography [in Russian], Ostek-SMT, Moscow (2015), pp. 24-25.

18. S. Karagadde, S. Sundarraj, and P. Dutta, "Modeling growth of hydrogen bubbles in aluminum castings using the level-set method," Scr. Mater., 61, No. 2, 216-219 (2009).

19. H. Meidani, J.-L. Desbiolles, A. Jacota, and M. Rappaz, "Three-dimensional phase-field simulation of micropore formation during solidification: Morphological analysis and pinching effect," Acta Mater., 60, Nos. 6-7, 2518-2527 (2012).

20. S. Karagadde and P. Dutta, "A comparison of time-scales governing the interaction and growth of hydrogen bubbles with a solidifying front," Int. Comm. Heat Mass Transf., 79, 16-20 (2016).

21. Q. Zhang, T. Wang, Z. Yao, and M. Zhu, "Modeling of hydrogen porosity formation during solidification of dendrites and irregular eutectics in Al-Si alloys," Materialia, 4, 211-220 (2018). 
22. S. V. Belyaev, B. P. Kulikov, V. B. Deev, et al., "Analysis of hydrogen content in the main stages of low aluminum alloy flat ingot manufacture," Metallurgist, 61, Nos. 3-4, 325-329 (2017).

23. S. V. Belyaev, E. G. Partyko, A. A. Kosovich, et al., "Analysis of plain aluminum saturation with hydrogen while adding different components," ARPN J. Eng. Appl. Sci., 13, No. 9, 3251-3256 (2018).

24. M. B. Djurdjević, Z. Odanović, and J. Pavlović-Krstić, "Melt quality control at aluminum casting plants," Met. Mater. Eng., 16, No. 1, 63-76 (2010).

25. D. Dispinar, S. Akhtar, A. Nordmark, et al., "Degassing, hydrogen and porosity phenomena in A356," Mater. Sci. Eng.: A, 527, Nos. 16-17, 3719-3725 (2010)

26. J. Zeng, D. Li, H. He, et al., "Relationship between aluminum oxide inclusion and porosity in aluminum melt," in: Proc. of the 8th Pacific Rim Internat. Congr. on Advanced Materials and Processing, Springer (2013), pp. 1157-1162.

27. H. Wang, G. Fu, C. Cheng, et al., "Molecular mechanics and dynamics simulation of hydrogen diffusion in aluminum melt," China Foundry, 14, No. 6, 478-484 (2017). 